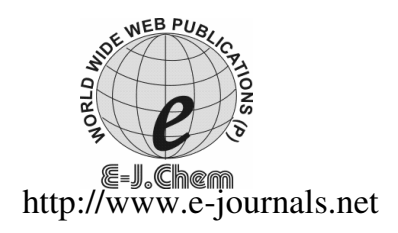

\author{
ISSN: 0973-4945; CODEN ECJHAO \\ E-Journal of Chemistry \\ 2011, 8(4), 1708-1713
}

\title{
The Effects of Cassia Siamea Lam. Root Extract on the Corrosion and Kinetics of Corrosion Process of Copper in Alkaline Solutions
}

\author{
A. I. ONEN* ${ }^{*}$ B. T. NWUFO ${ }^{\S}$ and E. E. EBENSO \\ *Department of Chemistry, Adamawa State University, P.M.B 25, Mubi, Nigeria \\ ${ }^{\S}$ Department of Chemistry, University of Jos, Plateau State, Nigeria \\ Department of Chemistry, North West University (Mafikeng Campus) \\ Private Bag X2046, Mmabatho 2735, South Africa \\ alfredonen@yahoo.com
}

Received 1 March 2011; Accepted 22 April 2011

\begin{abstract}
The effect of Cassia siamea lam. (CSL) root extract as a corrosion inhibitor of copper in $0.50 \mathrm{M} \mathrm{NaOH}$ solutions was investigated using absorbance difference technique at $30{ }^{\circ} \mathrm{C}$ and $40{ }^{\circ} \mathrm{C}$. CSL root extract inhibited the corrosion of copper in $0.50 \mathrm{M} \mathrm{NaOH}$ solutions and the inhibition efficiency (\% IE) increased to a maximum of $78.3 \pm 2.3 \%$ with increasing concentration of the extract but decreased with increasing temperature. The adsorption of CSL root extract on copper surface followed the Langmuir adsorption model with the average heat of adsorption, $Q_{\text {ads }}$ and free energy of adsorption, $\Delta \mathrm{G}_{\mathrm{ads}}$ of $-8.98 \mathrm{kJmol}^{-1}$ and $-8.70 \mathrm{kJmol}^{-1}$ respectively. A kinetic treatment of the data revealed a first order kinetics with respect to copper in the presence and absence of the extract.
\end{abstract}

Keywords: Copper, Absorbance difference, Alkaline corrosion, Kinetic parameter

\section{Introduction}

Metals and alloys are often exposed to the action of acids and alkalis in industrial processes thereby prompting their deterioration ${ }^{1}$. One of the most effective means of protecting metals and alloys surfaces from corrosion in acid and alkaline environments is the use of corrosion inhibitors ${ }^{2}$. Corrosion inhibitors are usually added to the acid/alkaline solutions to reduce the metal loss. Recently, studies on the use of drugs have been reported by several researchers ${ }^{3,4}$.

Some of these corrosion inhibitors are however, toxic to the environment. This has prompted the search for green corrosion inhibitors that are non-toxic and eco-friendly for metals and alloys in acidic and alkaline solutions ${ }^{5}$. These green corrosion inhibitors have been found to have centre for $\pi$-electrons and functional groups (such as $-\mathrm{C}=\mathrm{C}-$, - OR, $-\mathrm{OH},-\mathrm{NR}_{2},-\mathrm{NH}_{2}$ and $-\mathrm{SR}$ ) which provide electrons that facilitate the adsorption of the inhibitor on the metal/alloy surface. 
Research on the use of plant extracts as corrosion inhibitors for metals/alloys in acid or alkaline media has therefore been intensified ${ }^{1,5-18}$. This is because plants are rich sources of naturally occurring chemical compounds that are environmentally acceptable, cheap and readily available. For instance, Cassia siamea lam., CSL, is rich in several heterocyclic compounds ${ }^{7,13,14}$ of high molecular masses, with oxygen, nitrogen and sulphur atoms in their molecular structures.

Cassia siamea lam. leaf and stem extracts have recently been established as eco-friendly corrosion inhibitors of acid corrosion of mild steel ${ }^{8}$ and zinc $^{14}$. Available literature shows that there is no reported work on the inhibition characteristics/effects of Cassia siamea lam. root extract on alkaline corrosion of copper. This paper reports the effects of Cassia siamea L. root extract on both the corrosion of copper and kinetics of corrosion process of copper in $0.50 \mathrm{M} \mathrm{NaOH}$ solution using absorbance difference technique.

\section{Experimental}

Copper sheets $(98.7 \%)$ of $0.028 \mathrm{~cm}$ in thickness used for this study were obtained from Borno Wire and Nails Company Ltd in Maiduguri, Borno State of Nigeria. Each sheet was mechanically press cut into $4 \times 3 \times 0.028 \mathrm{~cm}$ rectangular specimens. The specimens were used as cut without further polishing to ensure reproducible surfaces ${ }^{1}$. They were however, degreased in absolute ethanol, rinsed with double distilled water, dried in propanone and stored in air tight desiccators before using them for this study ${ }^{8}$. The average mass of the specimens used was $15.28-15.33 \mathrm{mg}$ and the total surface area of the coupons exposed was $12.00 \mathrm{~cm}^{2}$.

The $\mathrm{NaOH}$ was of analytical grade; used without further purification and $0.50 \mathrm{M}$ of it was prepared and employed as the aggressive solution for the study. Cassia siamea Lam. roots were collected, washed, dried and pulverized. The extract was obtained from methanol $(\mathrm{BDH})$, using soxhlet extractors and concentrated using a rotary evaporator. A concentration range of $10^{0}-10^{1} \mathrm{mgdm}^{-3}$ (i.e. $1.0,3.0,5.0,7.0$ and $10.0 \mathrm{mgdm}^{-3}$ ) of CSL root extract was prepared in $0.50 \mathrm{M} \mathrm{NaOH}$ and used as inhibitor test solutions.

\section{Absorbance difference measurements}

The procedure for absorbance difference measurements was similar to that reported earlier ${ }^{8,14}$ but at a wavelength ${ }^{15}$ of $457 \mathrm{~nm}$ and at $30{ }^{\circ} \mathrm{C}$. The effect of temperature on the corrosion rate of copper specimens in $0.50 \mathrm{M} \mathrm{NaOH}$ at $40{ }^{\circ} \mathrm{C}$ was also investigated with different concentrations of $\left(10^{0}-10^{1} \mathrm{mgdm}^{-3}\right)$ of the extract.

\section{Results and Discussion}

The plot of absorbance difference (Add) of copper specimen versus inhibitor concentration at $30{ }^{\circ} \mathrm{C}$ for 168 hours ( 7 days) is shown in Figure 1. The absorbance difference decreased gradually as the inhibitor concentration increased. This indicates that CSL root extract inhibits the alkaline corrosion of copper in $0.50 \mathrm{M} \mathrm{NaOH}$ solution. The values of percentage inhibition efficiency (\% IE) were calculated for 24 hourly periods using the Equation (1)

$$
\% \mathrm{IE}=\left(1-\mathrm{A}_{1} / \mathrm{A}_{\mathrm{o}}\right) \times 100
$$

Where $A_{0}$ and $A_{1}$ are uninhibited and inhibited absorbance differences respectively ${ }^{1}$. Since there is a direct relationship between percentage inhibition efficiency (\% IE) and the degree of surface coverage $(\theta)$ for different inhibitor concentrations, the degree of surface coverage $(\theta)$ was determined using the expression

$$
\theta=\% \text { IE } / 100
$$




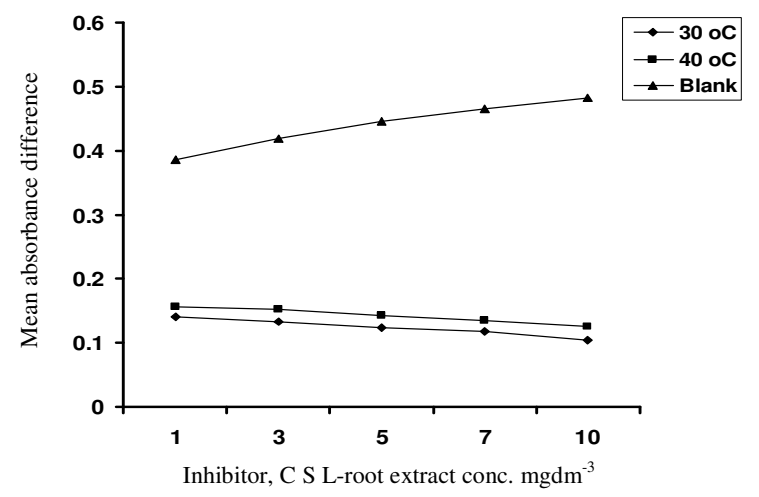

Figure 1. Plot of mean absorbance difference of copper specimen versus blank and inhibitor (CSL-root extract) concentration in $0.50 \mathrm{M} \mathrm{NaOH}$ solution for 168 hours at $30^{\circ} \mathrm{C}$ and $40{ }^{\circ} \mathrm{C}$

The percentage inhibition efficiency for 168 hours at $30{ }^{\circ} \mathrm{C}$ and $40{ }^{\circ} \mathrm{C}$ are shown in Table 1. The values of $\%$ IE as presented in Table 1 for triplicate copper specimens were precise to $\pm 2.3 \%$ indicating good reproducibility. Table 1 and Figure 2 reveal that $\%$ IE values increase with increasing extract concentration but decrease with increasing temperature. The highest $\% \mathrm{IE}$ of $78.3 \%$ was obtained at $10.0 \mathrm{mgdm}^{-3}$ concentration at $30{ }^{\circ} \mathrm{C}$.

Table 1. Summary of inhibition efficiency (\% IE), corrosion rates, $E_{a}$ and $Q_{a d s}$ of CSLroot extract on copper for 168 hours

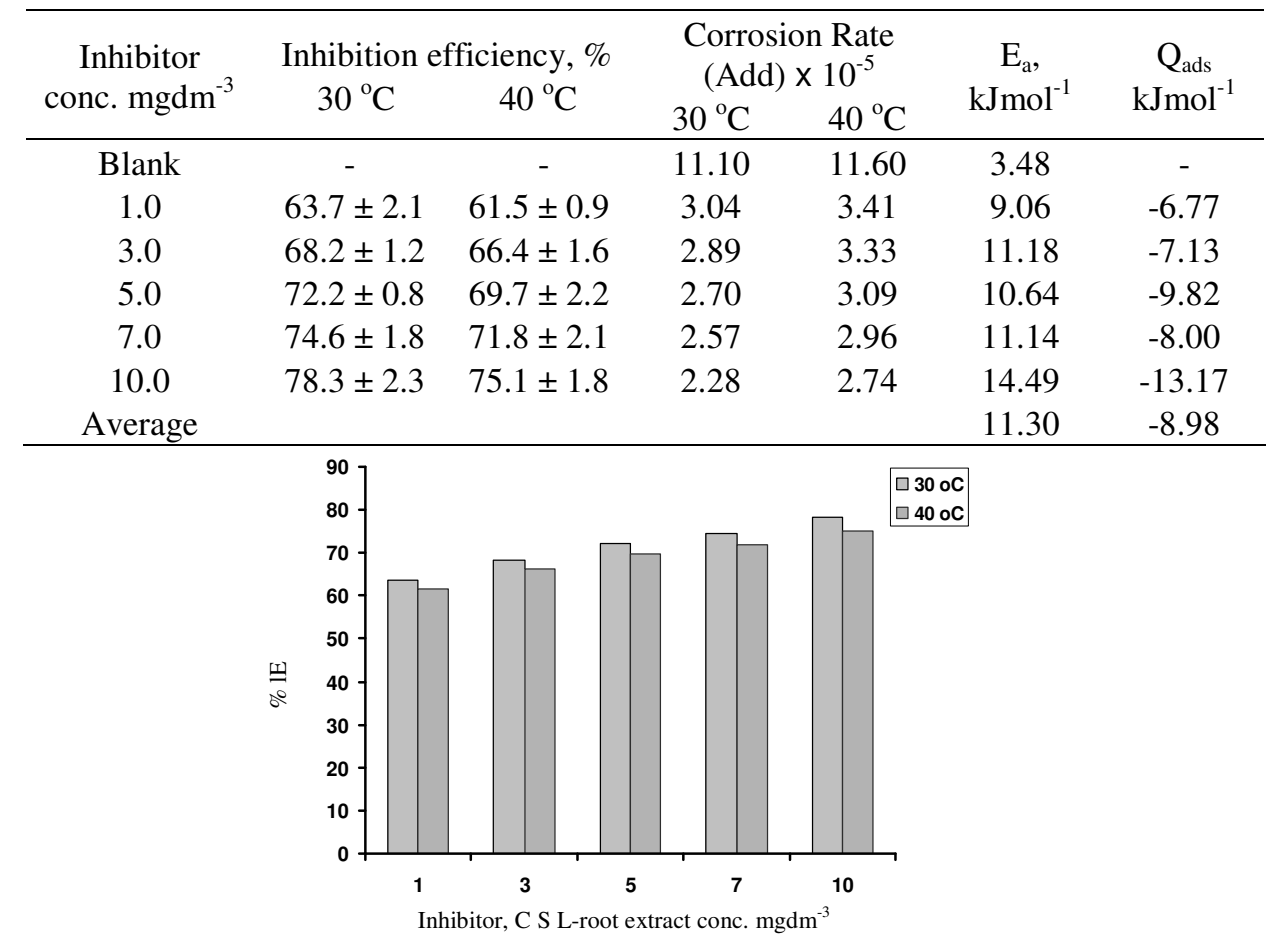

Figure 2. Plot of inhibition efficiency (\% IE) versus inhibitor (CSL-root extract) concentration in $0.50 \mathrm{M} \mathrm{NaOH}$ solution for copper corrosion at $30{ }^{\circ} \mathrm{C}$ and $40{ }^{\circ} \mathrm{C}$ 
The result suggests that increase in CSL root extract concentration increases the number of inhibitor molecules adsorbed on copper surface and reduces the surface area available for direct alkaline attack on the metal surface. This conforms to earlier findings of Abiola ${ }^{1}$, Valek and Martinez ${ }^{16}$. The inhibitive characteristics of CSL root may be due to the presence of organic compounds in the extract. Cassia siamea lam. extract is rich in many organic compounds including alkaloids, anthraquinones, glycosides, phenols, saponins, steroids and tannins ${ }^{8,13,14}$ of high molecular masses with hetero-atoms and $\pi$-centres in their molecular structures.

The inhibitory effect of Cassia siamea L root extract is therefore linked to the presence of these organic compounds in the extract. The fact that CSL root contains several compounds, antagonistic and synergistic effects may play significant roles on the inhibition effectiveness of the extract as an inhibitor. Organic compounds containing functional groups with $\mathrm{O}, \mathrm{S}$ or $\mathrm{N}$ and centre for $\pi$ electrons or combination of both have been reported as corrosion inhibitor of copper $^{16}$. The adsorption of these compounds on copper surface reduces the area that is available for the attack of the aggressive ion from the alkaline solution.

As observed in Figure 1, absorbance difference decrease with increase in root extract concentration due to higher degree of surface coverage, $\theta$ as a result of improved inhibitor adsorption. Similar views had previously been reported ${ }^{6,8,10,11,17}$. Figure 3 also confirms that the inhibition process is due to adsorption of the active organic compounds on the metal surface. This is because a straight line is obtained when $\mathrm{C} / \theta$ is plotted against $\mathrm{C}$ and the linear correlation coefficient of the fitted data is very close to 1 . This indicates that the adsorption of CSL root extract molecules obeys the Langmuir adsorption model ${ }^{10,18}$ expressed as

$$
\mathrm{C} / \theta=\mathrm{C}+1 / \mathrm{K}
$$

Where $\mathrm{C}$ is the inhibitor concentration and $\mathrm{K}$ is the equilibrium constant for the adsorption/desorption process of the inhibitor molecules on the metal surface. Values of adsorption parameters deduced from the plots are recorded on Table 2.

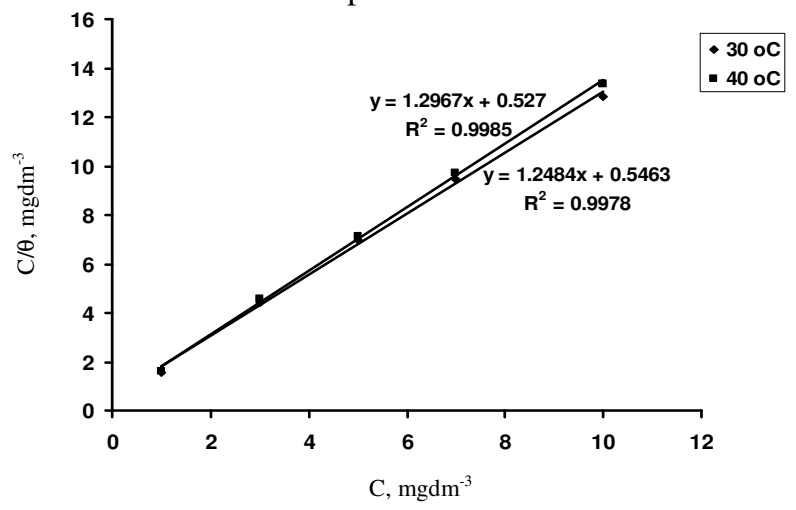

Figure 3. Langmuir adsorption model on copper surface of CSL-root extract in $0.50 \mathrm{M}$ $\mathrm{NaOH}$ solution for 168 hours at $30{ }^{\circ} \mathrm{C}$ and $40{ }^{\circ} \mathrm{C}$

The influence of the temperature increased (from $30{ }^{\circ} \mathrm{C}$ to $40{ }^{\circ} \mathrm{C}$ ) on the inhibitor efficiency is presented in Table 1 . Increase in temperature decreased the inhibitor effectiveness suggesting physisorption mechanism. The activation energy, Ea of the corrosion reaction was calculated using the rearranged Arhenius Equation (4);

$$
E a=2.303 R \frac{T_{1} T_{2}}{T_{2}-T_{1}} \log \frac{\rho_{2}}{\rho_{1}}
$$


Where $\rho_{1}$ and $\rho_{2}$ are corrosion rates at $30{ }^{\circ} \mathrm{C}$ and $40{ }^{\circ} \mathrm{C}$ respectively ${ }^{8}$. The heat of adsorption, $\mathrm{Q}_{\mathrm{ads}}$ was determined using Equation (5);

$$
\mathrm{Q}_{\text {ads }}=19.147\left(\log \frac{\theta_{2}}{1-\theta_{2}}-\log \frac{\theta_{1}}{1-\theta_{1}}\right)\left(\frac{T_{1} T_{2}}{T_{2}-T_{1}}\right)
$$

Where $\theta_{1}$ and $\theta_{2}$ are the values of surface coverage at $30{ }^{\circ} \mathrm{C}$ and $40{ }^{\circ} \mathrm{C}$. The values of Ea and $\mathrm{Q}_{\mathrm{ads}}$ are recorded in Table 1. The increase in Ea values in the presence of the inhibitor, with a decrease in $\% \mathrm{I}_{\mathrm{E}}$ of the inhibitor as the temperature increases further suggests physical adsorption of the inhibitor molecules on the copper surface. This is in agreement with the findings of other workers ${ }^{1,4,8,10,11,16,18}$. The values of $\mathrm{Q}_{\mathrm{ads}}$ are negative indicating that the adsorption process occurred exothermically. This observation further confirms physical adsorption of the inhibitor on the copper surface in $\mathrm{NaOH}$ solution. The relationship between the equilibrium constant, $\mathrm{K}$, of adsorption and the free energy of adsorption, $\Delta \mathrm{G}_{\mathrm{ads}}$, is given by the following expression ${ }^{3,16}$ :

$$
\Delta \mathrm{G}_{\mathrm{ads}}=-2.303 \mathrm{RT} \log (55.5 \mathrm{~K})
$$

Values of free energy of adsorption calculated from equation (6) using $\mathrm{K}$ values obtained from the Langmuir adsorption are presented in Table 2. The values are negative and less than $-40 \mathrm{kJmol}^{-1}$. This implies that the adsorption of the inhibitor on copper surface is spontaneous and confirms physical adsorption mechanism. This agrees with the findings of Valek and Martinez ${ }^{16}$.

Table 2. Values of Langmuir adsorption parameters and $\Delta \mathrm{G}_{\text {ads }}$ at $30{ }^{\circ} \mathrm{C}$ and $40{ }^{\circ} \mathrm{C}$

\begin{tabular}{ccccc}
\hline Temperature ${ }^{\circ} \mathrm{C}$ & Slope & $\log \mathrm{K}$ & $\mathrm{R}^{2}$ & $\Delta \mathrm{G}_{\mathrm{ads}}, \mathrm{kJmol}^{-1}$ \\
\hline 30 & 1.2484 & 1.4817 & 0.9978 & -8.60 \\
40 & 1.2967 & \multirow{2}{*}{1.4661} & 0.9985 & -8.79 \\
Average & & & & -8.70 \\
\hline
\end{tabular}

As shown in Figure 4, the corrosion data fit the first - order reaction rate law as expressed in Equation (7) ${ }^{1}$;

$$
\log \left[\mathrm{A}_{\mathrm{i}}-\Delta \mathrm{A}_{\mathrm{t}}\right]=-\mathrm{kt} / 2.303+\log \mathrm{A}_{\mathrm{i}}
$$

Where $A_{i}$ is the initial absorbance difference of copper specimen, $\Delta A_{t}$ is the absorbance difference of copper specimen at time $t,\left[\mathrm{~A}_{\mathrm{i}}-\Delta \mathrm{A}_{\mathrm{t}}\right]$ is the residual absorbance of copper coupon at time $\mathrm{t}$ and $\mathrm{k}$ is the first - order rate constant. The linear plots obtained with correlation coefficients close to 1 confirm a first - order kinetics for the corrosion of copper in $0.50 \mathrm{M} \mathrm{NaOH}$ solution in the presence and absence of CSL root extract.

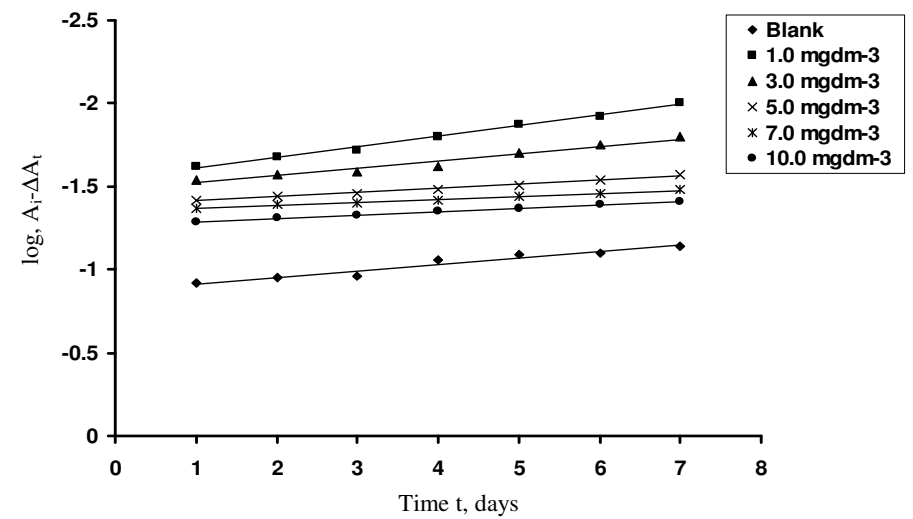

Figure 4. Plot of $\log \left[\mathrm{A}_{\mathrm{i}}-\Delta \mathrm{A}_{\mathrm{t}}\right]$ versus time, $\mathrm{t}$ (days) for copper specimens in $0.50 \mathrm{M} \mathrm{NaOH}$ solution with and without CSL-root extract at $30{ }^{\circ} \mathrm{C}$ 
The anodic reaction order with respect to copper is also reflected by Figure 4. [i.e. anodic reaction Equation (8)];

$$
\mathrm{Cu} \rightarrow \mathrm{Cu}^{2+}+2 \mathrm{e}^{-}
$$

This assertion has been reported earlier ${ }^{1}$. It can be inferred from the result (Figure 4) that the inhibition of alkaline corrosion of copper by Cassia siamea Lam. root extract has no effect on the anodic reaction order. A similar plot was obtained for copper in $\mathrm{NaOH}$ solution (blank) and with the CSL root extract.

\section{Conclusion}

The results of this study shows that the extract of Cassia siamea Lam. root inhibits the corrosion of copper in $0.50 \mathrm{M} \mathrm{NaOH}$ solutions, with the highest inhibition efficiency. (\% IE) of $78.3 \pm 2.3 \%$ at $10.0 \mathrm{mgdm}^{-3}$ extract concentration and \% IE decreased with increase in temperature. The mechanism of adsorption of the inhibitor molecules on the surface of copper is physisorption and is consistent with Langmuir adsorption model. A first order kinetics relationship was obtained from the kinetic treatment of the absorbance difference data.

\section{References}

1. Abiola O K and James A O, Corros Sci., 2010, 52, 661-664.

2. Ebenso E E, Arslan T, Kandemirli F, Caner N and Love I, Int J Quantum Chem., 2010, 110, 1003-1018.

3. Eddy N O, Ibok U J, Ebenso E E, El Nemr A and El Ashry E S, J Mol Model., 2009, 15, 1085-1092.

4. Onen A I, J Chem Soc Nig., 2007, 32(1), 227.

5. Oguzie E E, Corros Sci., 2007, 49, 1527-1539.

6. Onen A I, Nig J Appl Sci., 2004, 22, 174.

7. Okafor P C, Ebenso E E, Ibok U J, Ekpe U J and Ikpi M E, Trans SAET, 2003, 38, 91

8. Orubite-Okorosaye K and Oforka N C, J Appl Sci Environ., 2004, 8(1), 57-61.

9. Abdel-Gaber A M, Khamis E, Abo-ElDahab H and Adeel S h, Mater Chem Phys., 2008, 109, 297-305.

10. Abiola O K and Otaigbe J O E, Corros Sci., 2009, 51, 2790-2793.

11. Abiola O K, Otaigbe J O E and Kio O J, Corros Sci., 2009, 51, 1879.

12. Orubite K O and Oforka N C, Mater Lett., 2004, 58(11), 1768.

13. Lu T S, Yi Y H, Yuan H Y, Zhang Z G and Liu W, Medscape, 2003, 38(2), 113-315.

14. Onen A I, Maitera O N, Joseph J and Ebenso E E, Int J Electrochem Sci., 6, 2884-2897.

15. Obot I B, Obi-Egbedi N O and Umoren S A, Int J Electrochem Sci., 2009, 4, 863

16. Valek L and Martinez S, Mater Lett., 2007, 61, 148-151.

17. Abiola O K and Oforka N C, Scienta Africana, 2003, 2, 82.

18. Okafor P C, Ikpi M E, Uwah I E, Ebenso E E, Ekpe U J and Umoren S A, Corros Sci., 2008, 50(8), 2310-2317. 


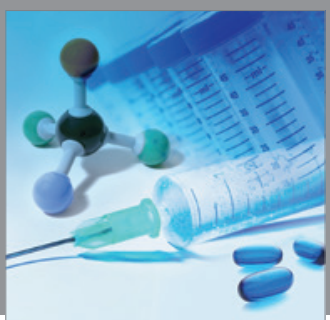

International Journal of

Medicinal Chemistry

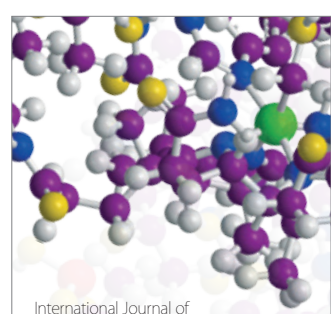

Carbohydrate Chemistry

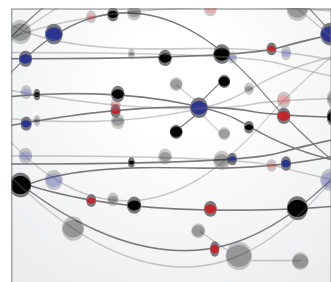

The Scientific World Journal
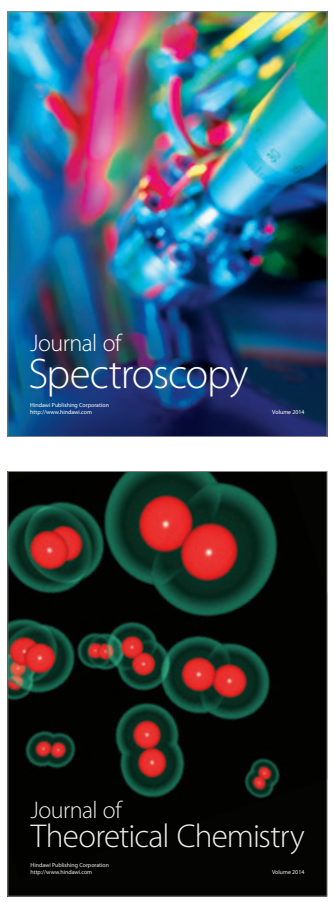
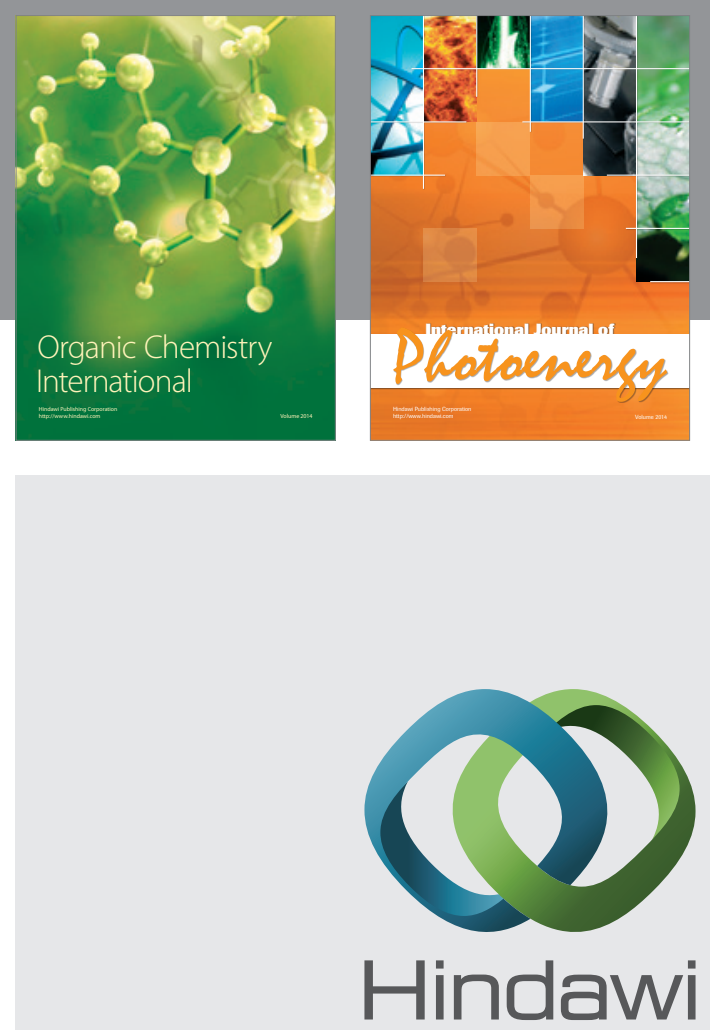

Submit your manuscripts at

http://www.hindawi.com
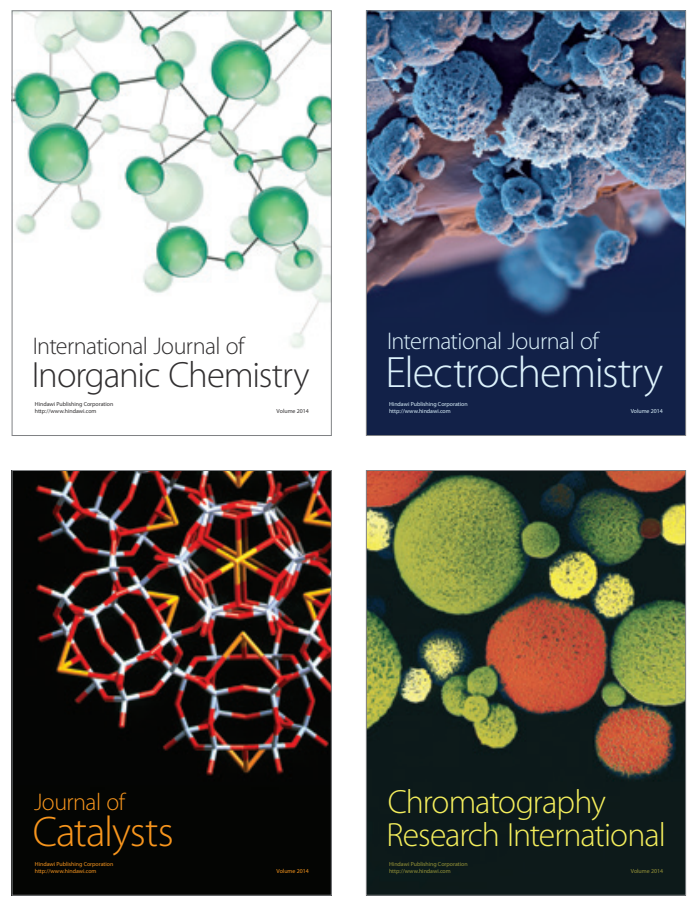
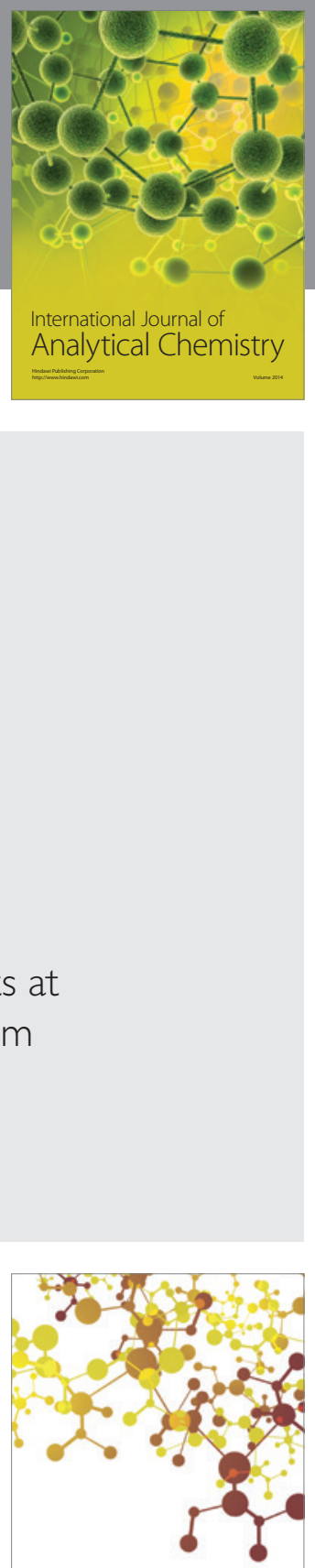

Journal of

Applied Chemistry
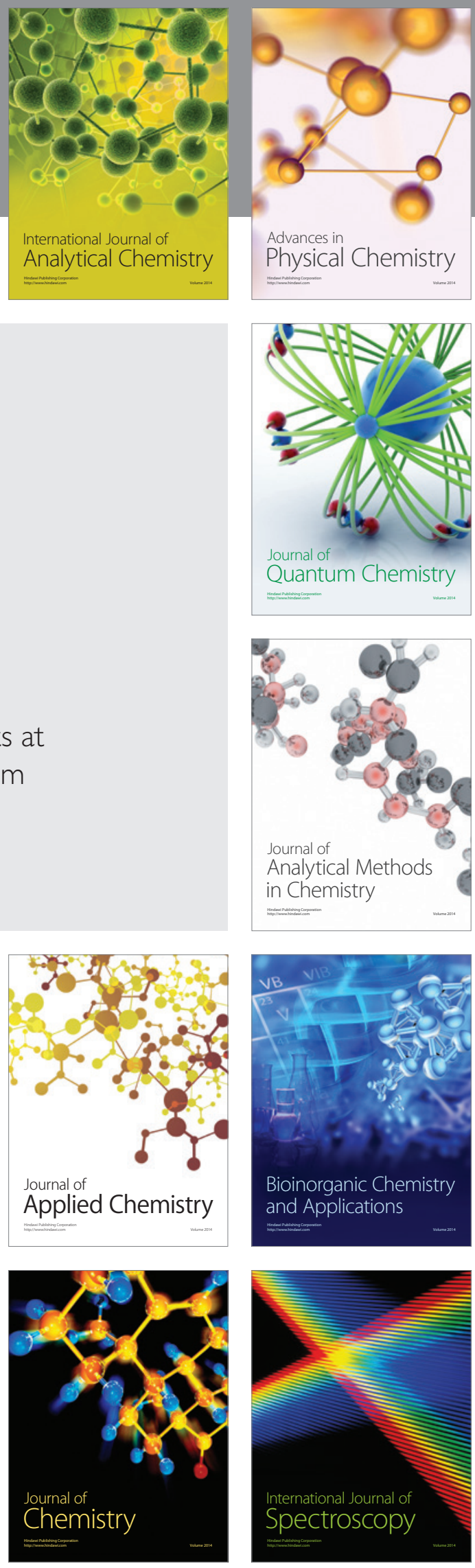